DOI 10.5216/ia.v44i2.56979

\title{
LOS EXPLORADORES DE DON BOSCO: LA EXTENSIÓN DE LA TAREA EDUCATIVA SALESIANA MÁS ALLÁ DE LAS PAREDES DEL AULA (SANTA CRUZ, S. XX)
}

\author{
Maria de los Milagros PierinI \\ Universidad Nacional de la Patagonia Austral, Santa Cruz, Argentina
}

\begin{abstract}
Resumo: La Congregación Salesiana nació en Turín cuando Italia se hallaba atravesando un proceso de industrialización y fuerte laicismo. El objetivo de esta Congregación fue atender a los niños y adolescentes de los sectores populares trascendiendo el ámbito meramente escolar. Al trasladarse a la Argentina replicaron la metodología implementada en Italia a la que sumaron a los Exploradores de Don Bosco. El objetivo de este artículo es mostrar cómo se desarrollaron en Santa Cruz durante el período de confrontación entre la escuela laica y la salesiana y entre los Exploradores de Don Bosco y los Boy Scouts. Utilizaremos la documentación brindada por ambas instituciones junto con los testimonios de los antiguos pobladores de Santa Cruz.
\end{abstract}

Palavras-chave: Salesianos, Santa Cruz, laicismo, Exploradores de Don Bosco, Boy Scouts.

INTRODUCCIÓN

Michel Foucault sostiene que la utilización y control del tiempo es una vieja herencia originada en las comunidades monásticas y rápidamente adoptados por las escuelas, los talleres y los hospitales. El principio subyacente de este empleo del tiempo era esencialmente negativo: el principio del "no - ocio" ya que se prohibía perder un tiempo que estaba en manos de Dios y, al mismo tiempo, se debía impedir el desperdicio del mismo utilizándolo de una manera cada vez más exhaustiva (FOUCAULT, 1975, p.175-176 y 180).

Este control del escolar y del tiempo también será visible en el sistema educativo salesiano con la implementación del "sistema preventivo" de Don Bosco en sus Oratorios Festivos desde mediados del siglo XIX, dirigido a todos los niños de la localidad, no sólo a los alumnos de sus colegios y, en el marco de los mismos, la organización que nos ocupa de los Exploradores de Don Bosco. Los mismos fueron creados en la Argentina a comienzos del siglo XX coincidiendo con una serie de iniciativas dirigidas a la formación de los adolescentes, de las cuales la más conocida es la británica de los Boy Scouts.

La implementación de la metodología salesiana en Argentina y en el Territorio 
Nacional de Santa Cruz se produjo en una época marcada por un fuerte laicismo y enfrentamiento entre el Estado Nacional y la Iglesia católica. La escuela fue uno de los ámbitos onde más claramente se evidenció este conflicto - en el caso que nos ocupa entre la escuela pública y la confesional a cargo de los salesianos- y del cual no escaparán los Exploradores de Don Bosco. El hecho de que en la década de su creación también hubiera comenzado a desarrollarse la Asociación argentina de los Boy Scouts y el propósito gubernamental de agrupar y ordenar una serie de formaciones de carácter similar y colocarlas bajo su dirección provocó el enfrentamiento entre los Exploradores de Don Bosco y los Boy Scouts. En el mismo se conjugaron distintos factores: el laicismo ya mencionado y los esfuerzos, por parte de la Congregación salesiana, de conservar la mayor autonomía posible frente a las gestiones estatales.

\section{UNA BREVE CONTEXTUALIZACIÓN DEL PERÍODO ESTUDIADO}

Desde la segunda mitad del siglo XIX la Argentina asistió a un proceso de transformaciones en todos los ámbitos de la vida nacional. Desde el punto de vista politico se produjo una concentración del poder en el gobierno central que luchó para que los poderes provinciales le estuvieran sometidos. En lo económico asistimos a la inserción en el Mercado internacional con el mandato de ser proveedora de materias primas- carne y cereales- para los mercados europeos (predominantemente el británico). La herramienta considerada fundamental para estas transformaciones fue la migración internacional por lo cual, desde el Estado Nacional, se proclamó una política sumamente generosa respecto al ingreso de las personas y las facilidades para el otorgamiento de la propiedad de la tierra (Ley de Migración y Colonización del año 1876). Sin embargo, mucho de lo estipulado por esta legislación no se cumplió o se hizo a medias debido a que existieron fuertes intereses, por parte de los grupos dominantes, para que no se permitiera el acceso a la tierra pública a los recién llegados y se continuara con la concentración en pocas manos. Por ese motivo muchos de los migrantes fueron obligados a trabajar como peones en los latifundios o mano de obra poco calificada en los centros urbanos que estaban en crecimiento.

De acuerdo con la ideologia de la época era "deseable" la migración europea, en especial la anglo sajona a la que se consideraba detentadora del progreso y la civilización y proveedora de la mano de obra "laboriosa" y "disciplinada" que era necesaria para la "nueva" Argentina. Aunque el mayor contingente migratorio europeo provino de España e Italia eso no impidió que se los siguiera valorizando como depositarios del progreso que se quería alcanzar. En forma paralela, se "invisibilizó" la proveniente de los países limítrofes que, en las regiones fronterizas, fue tan numerosa como la europea.

Pasadas las primeras décadas del ingreso masivo de migrantes, los beneficios pretendidos por el Estado nacional comenzaron a mostrar sus limitaciones: mientras la Argentina del Centenario pudo mostrar al mundo un grado de prosperidad destacado 
PIERINI, M. de los M.

también se evidenciaron las consecuencias no deseadas del proceso de inmigración masiva, la urbanización acelerada y la incipiente industrialización las que provocaron un alto grado de conflictividad social y la consiguiente respuesta represiva estatal. Años más tarde, cuando ya los movimientos anarquista y socialista habían perdido su peligrosidad, en las décadas de 1930 y 1940, el avance del nacionalismo creó un nuevo elemento que había que erradicar, en especial en los territorios patagónicos: el chileno.

La convocatoria al ingreso de migrantes internacionales se hizo sobre el supuesto de que la Argentina contaba con grandes espacios vacíos- que se calificaban como el "Desierto"que eran en realidad los ocupados por los grupos indígenas pre existentes a la conformación del Estado Nacional. A ellos les estuvo reservado el exterminio físico por medio de campañas militares 0 acciones privadas de los estancieros, la concentración en reservas estatales 0 reducciones religiosas $y$, para los sobrevivientes, la pérdida de sus pautas culturales y su inclusión como trabajadores asalariados en los establecimientos rurales.

El proceso de modernización también se produjo en la estructura de la Iglesia católica y se implementó por medio de la introducción de Congregaciones religiosas de origen europeo entre ellas la de los salesianos- y una mayor dependencia de la autoridad del Papado que se conoce como "romanización" (DI STEFANO; ZANATTA, 2000, p. 328 y 332).

Frente al aumento de la conflictividad social el Estado solicitó la colaboración de la Iglesia a quien le reconocía la función "civilizadora" ya que consideraba que por medio de la caridad y la enseñanza de los valores cristianos se podían inculcar las virtudes cívicas y el patriotismo entre los ciudadanos y, según las palabras del presidente Juárez Celman, "vacunar a la juventud contra la infección del socialismo y el nihilismo" (DI STEFANO; ZANATTA, 2000, p. 405 y 351 ).

\section{LOS EXPLORADORES DE DON BOSCO}

A comienzos de la década de 1840 Don Bosco llegó a la ciudad de Turín descubriendo la situación de los jóvenes que, en su mayoría, habían abandonado la vivienda familiar rural para trasladarse a las ciudades inmersas en el proceso de industrialización que estaba modificando la sociedad del norte de Italia. Frente a la pobreza y el abandono de la mayoría de ellos se preocupó por su contención desarrollando la institución ya existente en esa ciudad y en Roma de los Oratorios Festivos, el primero de los cuales nació en Turín el 11 de febrero de 1841. De acuerdo con las palabras del sacerdote José Vespignani el objetivo del Oratorio Festivo salesiano fue

\footnotetext{
hacer crecer al niño y al adolescente en relación con el desarrollo de todas las instituciones religiosas, morales, educativas y cívicas de su país; formarles al mismo tiempo un ambiente de expansión sano y alegre, bajo el amparo de la religión y la patria, representadas respectivamente por sus autoridades; atraer a la niñez pobre y desvalida a una morada de paz, de cariño, de ilustración y de virtud, que sea a la vez templo, escuela y familia (VESPIGNANI, 1918, p. 11).
} 
Los Oratorios fueron creaciones previas a los colegios salesianos y con una actividad dominical. Comenzaba con la confesión y la misa seguidos por un comentario de Don Bosco sobre pasajes de la Biblia. Luego del almuerzo los jóvenes tenían el recreo que era seguido por el catecismo y el rosario, posteriormente se proporcionaba una breve instrucción, canto de las letanías y bendición y luego se le daba el tiempo libre a los jóvenes hasta la noche. La despedida se hacía con las oraciones en la capilla que terminaban con un canto. En los mismos estaban siempre presentes la música, el teatro y las excursiones que eran considerados una herramienta educativa. Don Bosco consideraba a las excursiones el instrumento ideal para la formación de los jóvenes y promovió, desde un comienzo, las peregrinaciones a los santuarios. En otoño se realizaban excursiones de tres o cuatro semanas en las que se integraban el teatro, las bandas musicales y el canto que resultaban un elemento muy atractivo para las poblaciones por las que pasaban (VESPIGNANI, 1918, p. 31).

Dentro de la pedagogía salesiana la complejidad técnica, la destreza física y el decoro del cuerpo se entrecruzaron para lograr una propuesta educativa innovadora. El trabajo intenso, los ejercicios físicos repetitivos y la resistencia atlética estaban orientados a mantener en buen estado el cuerpo. La vestimenta, la higiene, la organización de los horarios para la recreación y el esparcimiento, la regulación del comportamiento en paseos, fueron aspectos complementarios de un sistema de formación complejo que no dejaba nada librado al azar. Además, estas estrategias constituyeron la base de técnicas y tácticas para gobernar el cuerpo, moralizar el comportamiento de los individuos y regular la convivencia social (FRESIA, 2004, pág. 3).

Dentro del espíritu y en el marco de los Oratorios Festivos nacieron en la Argentina los Exploradores de Don Bosco por gestiones de los sacerdotes salesianos José Vespignani y Lorenzo Massa. El primero menciona el 15 de agosto de 1915 como la fecha en que se inauguró en el colegio salesiano de Almagro (ciudad de Buenos Aires) el primer batallón de "Exploradores de Don Bosco" incorporándolo a las "Escuadras Gimnásticas" que reproducían los batallones escolares infantiles creados por Don Bosco en los Oratorios Festivos de Turín en 1842. Los Exploradores nacieron como un

medio de educación moral-cívica, para conservar en la niñez argentina, con el amor a la religión y con el cumplimiento de los deberes cristianos, especialmente en los días festivos, los nobles sentimientos del patriotismo, hermanados con el cariño de la familia, el respeto a las autoridades, en medio de una expansión legítima y de un sano compañerismo (VESPIGNANI, 1922, p. 353-354).

Específicamente se establecía que los Exploradores no debían reclutarse en los colegios salesianos sino entre los asistentes a los Oratorios y los talleres, con un objetivo muy claro de captar a los alumnos de escuelas laicas. Luego de la misa dominical tenían sus ejercicios físicos y mensualmente hacían una excursión a algún colegio salesiano. Tomaban 
PIERINI, M. de los M.

parte de los actos cívicos y hacían la guarda de honor con el fin de cumplir con el objetivo social y patriótico de la institución. Uno de los actos centrales era la jura de la Bandera a la que asistían autoridades eclesiásticas y civiles. Sus jefes e instructores eran elegidos por la Dirección o la Inspección del colegio entre los socios activos del Centro de ex alumnos. Con su palabra y ejemplo el explorador debía mostrarse como un "perfecto joven cristiano", estar adherido a la obra de Don Bosco y prestar su colaboración como catequista al Oratorio. La participación de los Exploradores en los actos oficiales tenía como objetivo la práctica de la formación religiosa y patriótica, el hacer conocer a la organización ganándose el apoyo de las autoridades civiles y el sostén económico de los cooperadores y el fomentar la camaradería entre los batallones (VESPIGNANI, 1918, p. 29).

Según palabras del fundador su lema era "Dios, Patria y Religión" y tenía como uno de sus objetivos competir con la atracción que ejercían los Boy Scout sobre los alumnos integrantes de los Oratorios Festivos. Sostenía Vespignani que "son una obra de educación popular que ha contribuído a reformar y a regenerar a la niñez pobre y callejera" agregando que "tienen la gran virtud de substraer a los niños de los juegos de la calle y de los hacinamientos de los conventillos e inquilinatos" y que

son un medio de educación física - moral - patriótica y religiosa para conservar en la niñez argentina, con el amor a la religión y el cumplimiento de los deberes cristianos, los nobles sentimientos del patriotismo, hermanados en el amor de la familia y el respeto a las autoridades (VESPIGNANI, 1918, p. 17, 73 y 105).

Desde un comienzo los Exploradores contaron con la colaboración del oficial de policía Ramón Cortés Conde, a quien el P. Massa colocó al mando y quien les dio una instrucción inicial similar a la de la escuela de Policía. Esta influencia también se hizo notar en la estructura interna, con muchas similitudes con la militar ya que los Batallones estaban integrados por oficiales y suboficiales, utilizaban toques de mando con tambor y clarín y tenían marchas y maniobras acompañadas con la banda.

En un comienzo los Exploradores adaptaron los principios del Scoutismo hasta que Vespignani elaboró la "Ley de Honor" y el "Reglamento y Programa de los Exploradores de Don Bosco" de acuerdo con el espíritu salesiano. El Decálogo de los Exploradores establecía el mandamiento del amor a Dios, el cumplimiento con su familia y con su patria, detestar la impiedad y la superstición, tratar de adquirir buenos hábitos, ser laborioso, previsor y ahorrativo, valiente y decidido en sus resoluciones. Con los diez preceptos de la Ley de Honor "se educa y se forma el criterio sano, la conciencia recta y el carácter firme e invencible del niño" (VESPIGNANI, 1918, p. 29).

Esta institución se implementó también en la Banda Oriental con la inauguración de un Batallón en el Oratorio León XIII de Maldonado a fines de 1915; en Paraguay desde 1938 y en 1921 existían los Exploradores en Turín cuyo nombre oficial era "Esploratori Cattolici Salesiani di Torino, III Reparto San Luigi" que tenían a los Exploradores argentinos como sus hermanos (CAPIZZANO, s/f, p.50). 
A pesar de sus buenas relaciones con las autoridades políticas, los Exploradores no fueron aceptados incondicionalmente por parte de la Congregación salesiana ya que existió un permanente temor por parte de sus autoridades de que las "exteriorizaciones" perjudicaran la vida espiritual de sus integrantes. Su mismo fundador, el P. Vespignani, poco antes de morir en 1931, criticaba el rumbo tomado por los Exploradores de Buenos Aires expresando que:

en general veo que se hace mucho ruido y pocas nueces, porque no se ven cumplir en sus Oratorios lo que corresponde a Exploradores de Don Bosco: no se habla sino de comparsas, ni un certamen catequístico, ni una función religiosa de primeras comuniones que ellos hayan concurrido a preparar", y agregaba que ya no eran capaces de hacer misión como en Salta y La Plata (CAPIZZANO, s/f., p. 50-51).

Desde el ámbito externo, los Exploradores fueron muy criticados, tanto desde la organización de los Boy Scouts que no logró incluirlos bajo su órbita, como por la prensa socialista que los consideraba, así como a toda agrupación similar, una "pérdida de tiempo y/o que escondía un móvil secreto de los 'frailes '" (CAPIZZANO, s/f., p. 35).

Los Exploradores también fueron influenciados por la acentuación del nacionalismo y el patriotismo en la década de 1940. Al respecto decía Juan José de Soiza Reilly en su discurso en ocasión de los festejos por el Centenario de la Obra Salesiana: "estos magníficos batallones [...] ponen sobre Buenos Aires la belleza de su gallardía y la altivez de su doble misión: por Dios y por la Patria!". Y en esa misma ocasión la Revista de Ex Alumnos hacía referencia a su sano patriotismo, calificándolos de "soldaditos de una causa grande", "sangre generosa y fuerzas vivas del porvenir de la Patria" (Revista Ex alumnos de Don Bosco, Octubre de 1941, p. 15181519).

En ocasión de los festejos por el aniversario mencionado los Exploradores fueron utilizados como un medio más para demostrar la masividad de la influencia alcanzada por la Congregación Salesiana en el campo de la niñez y la juventud y participaron de una concentración general en la Plaza del Congreso, en la ciudad de Buenos Aires, el 12 de octubre de 1941. La misa campal contó con la presencia del intendente municipal, Dr. Carlos Pueyrredón, la Presidenta de la Comisión Central de Cooperadoras Salesianas, Lola Acosta de Santamarina, el Presidente de los Boy Scouts Argentinos, Laureano Baudizzone y las autoridades de las Cooperadoras de la Patagonia, Isabel Nevares de Casares, Laurentina López de Pueyrredón y Raquel Balcarce de Binning. Al terminar la misa se efectuó la ceremonia de promesa de fidelidad a la bandera presidida por el presidente del Comando Sr. Ramón Cortés Conde (Revista Ex alumnos de Don Bosco, Octubre de 1941, p. 1509 - 1510).

Como una manera de reforzar el alcance de la actividad de los Exploradores y reconociendo que los mismos incluían a jóvenes que de otra manera se hubieran mantenido alejados, el Consejo Regional de los Ex alumnos de Don Bosco comenzó el 17 de septiembre 
PIERINI, M. de los M.

de 1951 las gestiones para regular las relaciones en cada una de las localidades entre los Centros de Ex alumnos y los Círculos de los Ex Exploradores de Don Bosco, proponiéndose que los Círculos de Ex Exploradores debían ser una sección del Centro local de los Ex alumnos (Archivo central salesiano. Buenos Aires. Caja de Ex alumnos. 199.11).

\section{LA ASOCIACIÓN DE LOS BOY SCOUTS}

La Asociación de los Boy Scout fue creada por Robert Baden Powell (1857 - 1941) en 1907 basándose en sus experiencias militares en la guerra anglo bóer y con la premisa de que los niños son capaces de las responsabilidades más grandes considerando que gracias a su formación se evitaría la "deteriorización nacional" y logrando que "el rango que está por perder, el Imperio lo recobrará" (Scouts católicos de Baden Powell, p. 6). En 1908 publicó "Scouting for boys", obra fundante de este movimiento, que estaba orientado a los jóvenes adolescentes de 10 a 16 años y que tenía como objetivo la formación del carácter. Su fundador la proyectó como un complemento, eminentemente práctico, de la escuela formulándole dos principios básicos: la confianza en el muchacho y la convicción de que para impedirle hacer el mal hay que dirigirlo hacia un bien real. Presenta, por lo tanto, una interpretación moderadamente optimista de la naturaleza humana ya que su fundador consideraba que en todo muchacho, aún en los de peor carácter, existía al menos un $5 \%$ de bondad y que era necesario desarrollarlo para llegar al 100\% (BERTOLINI, 1969, p. 37). Su Objetivo era enseñar a los niños cosas prácticas que pudieran serles de utilidad en la vida para valerse por sí solos; despertar nobles sentimientos y anhelos de ser hombres de provecho para la patria, para la sociedad y para sí mismos; inculcarles hábitos de orden, disciplina, compañerismo, altruísmo y limpieza; hacerlos valientes, sufridos, leales, honrados, fieles al cumplimiento del deber y de su palabra" (Scouts católicos de Baden Powell , p. 7-8). El sistema de patrullas, integradas por ocho niños y su jefe, es la base de la formación scout. También se decía expresamente que, aunque era una "escuela al aire libre", no era simplemente un deporte y que las excursiones y campamentos no se realizaban solamente por diversión sino que eran fundamentalmente formativos. Otra formulación expresa de su fundador, y en respuesta a quienes criticaban al movimiento por basarse en métodos militares, era que la instrucción y la disciplina militares formaban lo opuesto de lo pretendido por el Scoutismo que era la formación de personalidades individuales aunque con "virtudes militares" como el honor, la lealtad, la obediencia y el patriotismo.

Baden Powell había especificado en 1920 que "el Scout es ante todo un creyente: repudio todo scoutismo que no tenga como base la práctica de la religión". Por su parte, la Regla $3^{\circ}$ del Reglamento General se refería a la práctica religiosa de los scouts expresando que "se supone que todo scout pertenece a una denominación religiosa y practica sus oficios" y especificaba las medidas a tomar en los casos en que una tropa se compusiera de miembros de una misma religión o estuviera integrada por creyentes de diferentes religiones (Asociación Nacional Boy Scouts Argentinos, s/f., p. 8-9). 
La Organización se expandió rápidamente a nivel mundial. El 27 de agosto de 1908 nació el scoutismo en la República Argentina cuando, en la localidad bonaerense de Banfield, un grupo de jóvenes descendientes de ingleses tomó los ideales planteados por el fundador del movimiento y los llevó a la práctica. Este grupo era dirigido por Arturo Federico Penny, quien con la colaboración del doctor Daniel Inocencio Moreno -hermano de Francisco P. Moreno- organizó y dirigió las patrullas Foca y Aguila. Daniel Moreno brindó su quinta para que se realizaran los encuentros y organizó la Primera Compañía de Boy Scouts local, que se constituyó en la primera tropa de América (PODLUBNE; CHIAPPE; MÉNDEZ, 2009). Cuando, pocos meses después, en abril de 1909, Baden Powell visitó Argentina para dar una conferencia sobre la creación del movimiento fue recibido en el puerto de Buenos Aires por las dos patrullas ya conformadas. Durante su estadía en el país, se alojó en las instalaciones del Jockey Club de Buenos Aires como huésped de honor, siendo invitado por Christian Russell, secretario general de la Asociación Cristiana de Jóvenes de Buenos Aires. En la conferencia brindada planteó las bases del Scoutismo, aclarando que si bien en general se lo relacionaba con acciones militares, su interés estaba puesto en forjar hombres viriles y de carácter que respondiesen a las necesidades de un nuevo ciudadano para el mundo. Confianza en sí mismo, autodisciplina, caballerosidad, lealtad y patriotismo eran algunas de las virtudes necesarias a desarrollar en los jóvenes para mitigar la holgazanería y el vandalismo (PODLUBNE; CHIAPPE; MÉNDEZ, 2009).

Entre 1911 y 1912, con la participación de Francisco P. Moreno, Ángel Braceras Haedo y Tomás Santa Coloma, Gregorio Araoz Alfaro y Carlos Ibarguren entre otros, se extendió el socutismo por todo el país con el apoyo de los gobiernos provinciales. Una característica de esta implantación fue la prescindencia del carácter religioso que le había dado su fundador Baden Powell ya que muchos de los miembros fundadores pertenecían a la masonería - como ocurrió también en Santa Cruz y en la localidad chilena de Punta Arenas (MARTINIC, 20002001, pág. 162) y, décadas más adelante, el reforzamiento de su carácter militar y nacionalista para atender a la pretendida "homogeneización" de una sociedad multiétnica por lo cual se resaltaba en sus convocatorias su carácter patriótico (CAPIZZANO, p.15-16)

Según palabras de uno de los fundadores, Ángel Braceras Haedo, el Scoutismo era el gran colaborador de la escuela en la enseñanza del patriotismo, "la tabla de salvación" para que no se repitieran las escenas de la Semana Trágica

donde los niños, los niños escolares, eran los móviles de los sentimientos ácratas para por su intermedio hacer las barricadas de adoquines o carros que bien los daban vuelta, eran los niños los que ejecutaban estos planes y los que impedían la circulación de los tranvías, carros, coches, etc.

Concluye Braceras Haedo en que la obra de la Asociación Nacional Boy Scouts no debe de ser confundida con la de otras agrupaciones ya que, para los Boy Scouts "ante todo está la Patria y los hombres que por ella nos dieron libertad" (BRACERAS HAEDO, 1919, p.160 
PIERINI, M. de los M.

- 162). En un país caracterizado por su heterogeneidad étnica producto de las migraciones a la Asociación de los Boy Scouts se le otorgó, además, la función de ser:

el crisol que servirá para fundir las diferentes razas y producir el pueblo argentino homogéneo del futuro, con aspiraciones bien definidas, con orientaciones de trabajo, de lucha, con conciencia nacional, de igualdad democrática, de noble emulación y de sanas energías. [...] El scoutismo busca la igualdad de todos sin distinción de clases, de razas, ni de creencias [...] Es, pues, una institución altamente democrática que trata de generar una hermandad de todos sus miembros; hermandad que en un provenir no lejano, contribuirá eficazmente a la paz social y a la paz universal (La Unión, 24.8.1929).

El carácter laico del Movimiento Scout hizo que el sacerdote salesiano J.B. Magaldi lo acusara de pretender "descristianizar a la juventud destruyendo la espiritualidad de los niños que ingresan a él" (MAGALDI, 1939, p. 384).

En 1925, la Asociación inició un plan de propaganda nacional que contó con el apoyo de los gobiernos locales logrando la creación de numerosas asociaciones en el interior de la Argentina que debían organizarse en cada localidad de acuerdo con el Reglamento y dependiendo directamente de la Junta Ejecutiva. Las asociaciones locales gozarían de amplia autonomía debiendo subvenir a sus propias necesidades y serían controladas por Inspectores regionales designados por la Junta Ejecutiva Nacional. En los Territorios Nacionales de Neuquén y Río Negro se organizaron -en la década de 1930 - las agrupaciones de los Boy Scouts, bajo la influencia militar y policial ya que se confiaba en que la militarización de la juventud la alejaría del socialismo y estimularía los sentimientos patrióticos (BOHOSLAVSKY, 2003, p. 56)

En la década de 1930 se inició en la Argentina el movimiento Scout católico, que había nacido en Francia el 17 de enero de 1921 contando con la bendición papal, por la iniciativa del obispo de Buenos Aires, Monseñor Copello, en una parroquia de Buenos Aires. Logró, desde los inicios, una gran cantidad de adherentes y pudo rivalizar con éxito con el movimiento scout de tendencia liberal. Zanatta señala a este movimiento como una prueba de la influencia creciente del Ejército y la Iglesia en el campo educativo a partir de la década de 1930, agregando que "es significativo que el Directorio de los scouts católicos estuviera integrado por numerosos oficiales, sacerdotes y militantes de diversas tendencias" (ZANATTA, 1996, p. 320).

A nivel europeo la agrupación Scout fue absorbida, o eliminada como en el caso italiano en 1927, por los movimientos de ideología fascista con el fin de crear asociaciones juveniles e infantiles propias.

\section{EL CONFLICTO ENTRE LOS EXPLORADORES DE DON BOSCO Y LA ASOCIACIÓN DE LOS BOY SCOUTS}

Ante la diversidad de asociaciones similares que existían y con el objetivo fundamental de reunirlas "para que no se degenere ni desvirtúe la enseñanza del scoutismo haciéndolo servir de (sic) intereses extraños a su finalidad" el decreto del Poder Ejecutivo 
Nacional del 13 de noviembre de 1917 declaró al Scoutismo institución nacional resaltando su patriotismo y su finalidad "netamente nacional y educativa" y colocando su organización, dirección y fomento en todo el país bajo la dependencia y contralor de la Junta Ejecutiva de la "Asociación Nacional Boy Scouts Argentinos". Se establecía de este modo que "ninguna institución, sociedad o particular podrá, en lo sucesivo, organizar ni tener grupos de scouts sin autorización escrita de dicha Junta Ejecutiva". Por decreto del 15 de junio de 1918 se aprobó el Reglamento General y Programa de Trabajo de la "Asociación Nacional de Boy Scouts Argentinos" fusionando bajo su dirección a los grupos existentes (VESPIGNANI, 1918, p. 65 69).

Esta unificación y el intento por parte de la comisión directiva de los Scout de regir todas las instituciones similares originó un largo conflicto con la asociación de los Exploradores de Don Bosco logrando los salesianos reafirmar la diferencia de concepción entre ambas agrupaciones y mantenerse independientes, lo que fue avalado por decisión del Ministerio de Guerra el 10.12.1917, y ante la insistencia durante 1918 por parte de los Scouts, llegando Vespignani a amenazar con disolver a los Exploradores antes de someterlos a los Scouts, el Poder Ejecutivo Nacional reiteró la decisión de mantener la independencia entre ambas instituciones. En su larga empresa por la independencia, que incluyó numerosas cartas a las autoridades políticas entre ellas al presidente Hipólito Yrigoyen, José Vespignani señalaba que los exploradores tenían su origen en una institución de Don Bosco anterior a la creada por Baden Powell, su finalidad era educativa, estaban integrados por alumnos y directivos del colegio, los ejercicios gimnásticos se alternaban con la recitación y la música, no se permitían los campamentos y patrullas, y las excursiones eran a los mismos colegios salesianos. Solicitaba que no se los confundiera con "instituciones puramente deportivas y de reciente creación" (VESPIGNANI, 1918, p. 79, 83,108).

\section{LA SITUACIÓN EN SANTA CRUZ}

Santa Cruz fue una región de poblamiento migratorio, con una baja densidad que, recién en el Censo de 2010 alcanzó a 1 hab/ $\mathrm{km}^{2}$, la cual estaba concentrada mayoritariamente en las localidades de la costa atlántica y se caracterizaba además por el aislamiento producido por las grandes distancia y los deficientes medios de comunicación. La región estuvo, hasta la década de 1940, inserta en una economía ovina exportadora hacia el mercado británico. A nivel político -desde el año 1884 y hasta 1957 - Santa Cruz fue un Territorio Nacional por lo cual su dependencia del gobierno central era absoluta. Entre las décadas de 1880 a 1930 Santa Cruz estuvo fuertemente integrada a la región magallánica chilena cuya capital es Punta Arenas. Esta integración incluyó también a la Congregación salesiana. Durante la década de 1940 los territorios australes fueron objeto de un nuevo interés que estaba centrado en su valor estratégico y como proveedores de recursos energéticos - hidrocarburíferos y carboníferos - para la incipiente industrialización. Esta situación produjo cambios en las 
PIERINI, M. de los M.

estructuras económica y demográfica con el arribo de nuevos contingentes poblacionales argentinos.

En el campo religioso existió, en todos los Territorios patagónicos y no sólo en el de Santa Cruz, un virtual monopolio de la Congregación Salesiana por lo cual podemos coincidir con las palabras del historiador jesuita Guillermo Furlong cuando expresa que "si 'Misiones' en lo que respecta a la provincia así llamada, es sinónimo de 'Jesuitas', 'Patagonia' y sus divisiones de Neuquén, Chubut, Santa Cruz, son sinónimo de la palabra 'Salesianos'" (FURLONG, 1971, s/f).

En el año 1885 el Gobernador de Santa Cruz, Carlos Moyano, solicitó un capellán a los Salesianos debido a lo cual en noviembre de ese año llegaron a la capital - Puerto Santa Cruzlos sacerdotes José María Beauvoir y Ángel Savio. (BRUNO, 1981, p. 412) La lejanía de la sede central que la Congregación salesiana había instituido en Viedma (Patagonia septentrional) hizo que el circuito de conexiones y recorridas de los misioneros salesianos estuviera en una órbita cuyo centro era la ciudad chilena de Punta Arenas y que incluía la Isla de Tierra del Fuego - tanto la sección chilena como la argentina- y las islas Malvinas. La mayor dificultad de esta extensa región fueron las distancias de un punto al otro y el aislamiento de sus escasos habitantes por lo cual los misioneros debían recorrer grandes distancias para evangelizar (NICOLETTI, 2008, p. 90-91).

En cuanto a la evangelización, los sacerdotes implementaron el sistema de misiones itinerantes $y$, de manera similar a lo ocurrido en Tierra del Fuego, las breves misiones a los indígenas de Santa Cruz tuvieron la enorme dificultad de luchar contra la extinción de estas comunidades. El alcance efectivo de la evangelización fue relativo y el resultado fue la discriminación, la marginación y, en algunos casos la extinción total de los indígenas. La vuelta de los indígenas patagónicos a prácticas rituales anteriores a la presencia de los salesianos y el silencio de los indígenas fueguinos en lo referido a su cosmogonía religiosa fueron los síntomas latentes de su resistencia. Esta situación puede explicar el por qué la tarea salesiana en Santa Cruz se concentró fuertemente en la educación en los centros urbanos optando por el otro grupo marginal que era el de los inmigrantes y sus hijos (NICOLETTI, 2008, p. 92, 191 194).

En el caso especifico de la tarea que desempeñaron en la cercana isla de Tierra del Fuego, los misioneros salesianos y las Hijas de María Auxiliadora arribaron cuando el conflicto entre indígenas y "blancos"- estancieros, buscadores de oro y loberos- estaba en pleno desarrollo y se había acorralado de tal manera a los fueguinos que el proceso de extinción no se hizo esperar. Creyeron que únicamente la metodología de Misión podía frenar el exterminio que estaban sufriendo los indígenas pero, lamentablemente, el método resultó contraproducente porque, si bien la vida reduccional puso un tope a las matanzas indiscriminadas la implementación de nuevas pautas culturales- consideradas por los misioneros como "civilizadas" - como los cambios en la alimentación y la vestimenta, la erradicación del nomadismo y las actividades sedentarias y rutinarias sumadas al sistema de poblado cerrado aceleró el contagio de enfermedades y la propagación de epidemias como viruela, tuberculosis y sarampión (CASALI, 2013, p. 88). La Misión de San Rafael (isla Dawson) 
cerró en 1911, la de La Candelaria (Río Grande) lo hizo en 1923; el año anterior habían cerrado las de Lago Fuego y Lago Fagnano (NICOLETTI, 2008, p.185).

Los obstáculos a la metodología de la Misión fueron, de acuerdo con los testimonios de los sacerdotes y religiosas, la relación violenta con "el blanco", el anti testimonio de los cristianos y la fuerza que sostenía la religión indígena ya que la profundidad de los conceptos religiosos de los selk'nam y la falta de exteriorización de los mismos por temor, respeto y veneración hacia su Dios condicionó la interpretación de quienes se acercaron a ellos para conocer su mundo espiritual (NICOLETTI, 2008, p.171).

En el Territorio de Santa Cruz y de manera paulatina, superados los escollos iniciales - entre los que podemos mencionar el fuerte laicismo de las autoridades del Territorio, la escasez de habitantes, la predominancia entre los mismos de la ideología socialista, la rigurosidad del clima y las grandes distancia- la Congregación salesiana fue afianzándose hasta convertirse en la única representación de la Iglesia católica y la monopolizadora de la educación privada. Como ocurrió en los otros lugares de la Argentina, su acción tendió siempre a trascender la esfera educativa centrada en la escuela y por ese motivo también crearon Batallones de Exploradores de Don Bosco.

\section{LOS EXPLORADORES DE DON BOSCO EN SANTA CRUZ}

Es de señalar que, en Santa Cruz, la acción salesiana priorizó la esfera escolar por sobre la de los Oratorios Festivos aunque en el caso de los Exploradores continuaron con el objetivo de atraer a los alumnos de las escuelas públicas laicas. Ya a comienzos de la década de 1920 encontramos referencia a su existencia y atractivo entre los niños en la prensa local aunque refiriéndose a ellos como "sociedad de Educación Física" (El Nacional, 15.10. 1923).

También en Santa Cruz los Exploradores contaron con la aprobación de las autoridades políticas del Territorio y, a semejanza del perfil militarista otorgado en Buenos Aires, el Gobernador Germán Vidal designó al Sargento de Policía Domingo Varela, el 12 de septiembre de 1923, como instructor del Batallón de Exploradores de Don Bosco en reemplazo de Roberto Doblesky (La Unión, 2.11. 1922).

Podemos suponer que este Batallón dejó de existir ya que en junio y diciembre del año 1929 se realizaron diversas actividades teatrales con el fin de recaudar fondos para crear los cuerpos de Exploradores y Legionarios. Pero recién a comienzos de 1941 se constituyeron con la presencia del capitán Francisco Geronazzo viajado especialmente desde Buenos Aires para establecer las bases del batallón. El mismo poseía las secciones de Comunicaciones, Sanidad, Banda y jefatura. Debido a que carecían de los elementos básicos el Director del colegio Salesiano envió varias notas pidiendo la cooperación pública para la compra de sus uniformes (La Unión, 19 y 21.4 y 17.5.1941). Así como en el colegio de Río Gallegos, se crearon Batallones de Exploradores en los restantes colegios del Territorio; en la localidad de Puerto 
PIERINI, M. de los M.

Deseado desde julio de 1926 y en el colegio de San Julián desde agosto de 1934 (El Orden, 3.5.1945).

En todas las localidades participaban de los actos patrios con desfiles cívico militares y la promesa de fidelidad a la bandera, colaborando además con su banda. Sus actividades tenían un fuerte carácter patriótico, en especial la ceremonia de la promesa de fidelidad a la Bandera que adquiría una gran importancia y en la cual las palabras dirigidas por el director del colegio y capellán del batallón hacían alusión a los deberes patrióticos (El Orden, 17.5.1945). Las actividades de los Exploradores contaban con la presencia de las autoridades políticas y eran amplia y elogiosamente difundidas por la prensa local. También fueron habituales las visitas de sus batallones a los demás colegios de la costa atlántica y el intercambio con los Batallones que estaban en el colegio San José de Punta Arenas (La Unión, $15,18,20$ y 251.1940$)$.

\section{LOS BOY SCOUTS EN SANTA CRUZ}

Una de las características de la vida de esta Institución fue su evolución con interrupciones y los permanentes intentos por reorganizarla. Las primeras referencias encontradas sobre los Boy Scouts son las menciones a la Compañía organizada en Río Gallegos bajo la dirección del Sr. Jáuregui en el año 1916. Frente a la crisis que vivía la organización producto en parte de "la desconcertante apatía que caracteriza a nuestro medio" -, en el año 1922 hay un nuevo intento, por parte del jefe de policía, Capitán Schweitzer , de convocar niños para integrar la Brigada. Agregaba la crónica periodística que "la importancia de los Boy Scouts se observa en la organización a nivel nacional que cuenta con personería jurídica y en Río Gallegos es más importante debido a la carencia de centros o lugares que atraigan a la niñez". El periódico hacía un llamamiento para "evitar el parasitismo de nuestra juventud alejándola de las solicitaciones de la calle" y de que caiga en la "morbosa atracción del alcohol o del juego de azar" (El Nacional, 26.1, 1.2 y 10.3.1922).

Al año siguiente, hay referencias a Boy Scouts en Puerto Santa Cruz con cincuenta inscriptos. La Comisión de Fomento de esa localidad le concedió, en 1927, el permiso de ocupación de un terreno en el pueblo para la compañía contribuyendo también con la suma de cien pesos.

En 1927 Lucas Nicolitch organizó y fundó el cuerpo de los Boy Scout de Río Gallegos con la ayuda de Rosario Grillo, gerente de la tienda "La Mercantil" y el sargento de policía Maldonado con el nombre de "Compañía San Martín de Boy Scouts Argentinos". Según las crónicas periodísticas tenía un equipo de fútbol de tercera división (La Unión, 28.1 y 23.2.1929). A comienzos de 1930 se renovó la Comisión de Fomento confirmando a Lucas Nicolitch como maestro scout. El periódico La Unión que da cuenta de esta Comisión también la exhorta a hacer una activa propaganda entre los padres de familia acerca de las funciones educativas de los Boy Scouts junto con los beneficios derivados como son "la modelación del carácter para que surjan hombres laboriosos, disciplinados, decididos a cumplir una misión en la vida, misión de progreso, de amor, de conciencia de los propios deberes". Mientras que 
elogia lo que ha hecho en tan poco tiempo esta Comisión, el periódico observa que "nos está pareciendo que no hay ya, en el seno de la Comisión de Fomento, el entusiasmo de otros tiempos" (La Unión, 25.3.1930).

Dos años más tarde, a comienzos de 1932, comenzaron las tratativas para constituir la Junta Territorial de los Boy Scouts Argentinos lo que se logró el 29 de enero con la participación de integrantes destacados de la comunidad.

Las noticias de los periódicos locales nos permiten suponer que la vida de esta institución no transcurrió sin sobresaltos ya que hay varias referencias a los intentos de reorganización de la misma, siempre con la presencia de miembros de la elite local.

Aunque la memoria local considera a Félix Valenciano el fundador de los Boy Scouts en la localidad de Piedrabuena (llamada Paso Ibáñez) éstos habían sido creados años antes con el apoyo de la comunidad local siendo organizados por el agente policial Silvestre Mauro, que tuvo a su cargo la instrucción de los cuarenta integrantes (La Unión, 15.5.1928 y 10.12.1929).

Félix Valenciano, también agente policial, fue apoyado por la escuela y la comisión de fomento en su tarea con los Boy Scouts. Al año siguiente de su arribo a la localidad, en 1928 tuvo la iniciativa de fundar la Compañía de Scouts "Domingo Faustino Sarmiento" integrando a niños y niñas la que llegó a ocupar un lugar destacado entre las demás del país. A fines de 1929 las gestiones de la Asociación Nacional consiguieron que los integrantes de la Compañía Sarmiento contaran con una rebaja del cincuenta por ciento en los pasajes de tercera clase en los barcos de la Compañía General Argentina de Navegación. En 1930 Valenciano quiso premiar a los mejores Boy Scouts de su compañía por su buen comportamiento y organizó una excursión a Buenos Aires de la que participaron doce jóvenes. Una vez en la ciudad capital el contingente se alojó durante varios días en el Hotel de los Inmigrantes, visitaron lugares históricos de la ciudad y conocieron a músicos y cantantes famosos de esa época. Una de las gestiones que realizó la compañía de los Boy Scouts fue la de solicitarle al presidente Hipólito Yrigoyen - en una entrevista con el Ministro del Interior - que se le impusiera al pueblo el nombre de "Comandante Luis Piedrabuena" y pronto el pedido fue aceptado (La Unión, 24.9.1930).

Al ser trasladado a la localidad de Perito Moreno Valenciano fundó el Tiro Federal y se desempeñó en el cargo de Juez de Paz de la zona del lago Buenos Aires. En 1944 fue destinado a la Gobernación militar de Comodoro Rivadavia. Falleció en Puerto Deseado en 1952 (BEECHER, 2006).

Los informes oficiales de la Organización de los Boy Scouts mencionan - en la década de 1940 - como Delegado General en el Territorio de Santa Cruz a su Gobernador, el Capitán de navío Juan Manuel Gregores (ex alumno salesiano) indicando que existían en esa fecha las Asociaciones de las localidades de Comandante Luis Piedrabuena, Colonia Las Heras, Paso Roballos y Puerto Santa Cruz (Boy Scouts Argentinos, 1941 - 1942, p.41). La Institución de los Boy Scouts de Santa Cruz fue languideciendo paulatinamente hasta desaparecer a los pocos 
PIERINI, M. de los M.

años. Reaparecerá recién en la década del ' 60 y, acorde con los cambios sufridos a nivel nacional, exclusivamente con la impronta católica y parroquial.

No observamos trazas del conflicto que se había suscitado, a nivel nacional, entre los Exploradores y los Boy Scouts y podemos atribuirlo a la decadencia de la segunda organización a nivel provincial, como ya mencionamos, y a que, la principal fuente de conflicto entre ambas que radicaba fundamentalmente en la orientación laicista de una y católica de los salesianos, al volverse predominantes los scouts católicos en la década de 1940 estaba, por ende, muy atenuada. Un dato muy ilustrativo de esta afirmación es que, en la comisión para la reorganización de la institución de Río Gallegos, en 1939, están presentes el director del Colegio salesiano, el director de la Cárcel local, el jefe del destacamento de Artillería de Costas y reconocidos masones locales.

Un dato para tener en cuenta es que en Trelew y Rawson existían, en la década de 1920, los "Boy Scouts" en los colegios salesianos, con una orientación cívico-militar y con "el objetivo de afianzar los valores del Estado bajo los ideales católicos y nacionalistas" (MONZON, 2003).

\section{ALGUNAS CONCLUSIONES}

Las instituciones de los Boy Scouts y los Exploradores de Don Bosco nacieron casi simultáneamente con un fuerte sentido formativo y de complemento de la educación escolar y orientadas a captar al mismo grupo de población: los niños y adolescentes. En el caso de la Congregación salesiana brindando, o completando, las enseñanzas religiosas y, en cuanto a los Boy Scouts, aportando la educación práctica y la vida en la naturaleza de las que carecía la escuela tradicional.

Coincidieron con otras posturas pedagógicas de la época en las prácticas para la formación del carácter, el control del cuerpo y en una apreciación bastante negativa de la vida moderna a la que acusaban de que, con las "comodidades" brindadas por la tecnología, amenazaba con hacer perder la virilidad y "afeminar" a los niños y adolescentes. Analizándolo desde una perspectiva de género resultaba un discurso profundamente misógino que consideraba que las virtudes del futuro ciudadano eran únicamente las atribuidas al género masculino y que las que poseían las mujeres eran algo negativo y que había que corregir.

Más explícitamente en los discursos de Baden Powell y siendo la columna vertebral de las posturas de la Iglesia católica está el propósito por recuperar "lo perdido"; en el caso del fundador de los Boy Scouts el que sus jóvenes fueran los responsables de la recuperación de un Imperio británico que comenzaba a mostrar signos de declinación y, en el de Iglesia católica el regreso a una época - que podríamos calificar de mítica- en la cual la Iglesia era la Magister Vitae.

En el caso específico de los Exploradores de Don Bosco-a los que podríamos calificar de "institución peri - escolar" todas las actividades desarrolladas podían llegar a ser formadoras y un excelente complemento de los Oratorios Festivos y los colegios de la Congregación. Gracias a ellos la influencia salesiana trascendía las paredes de la escuela, iba en busca de los niños y jóvenes que, por diversas razones, no asistían a sus establecimientos 
y a través de ellos y las actividades públicas realizadas llegaban a la comunidad en una tarea simultánea de formación y difusión de su tarea y principios.

Podemos ver en los intentos realizados por José Vespignani, entre los años 1917 y 1918, por diferenciar a los Exploradores de los Boy Scouts, además de su objetivo explícito de no pasar a depender de su conducción liberal, la voluntad por afirmar su identidad. Pero ésta es una identidad que, a simple vista, se confunde con facilidad entre unos y otros. Por tal motivo es que nos parece tan poco convincente su demostración y que, para algunos testimonios de los primeros años de existencia, los Exploradores se confundieran con los "Boy Scouts salesianos" como en el caso de los colegios del Territorio del Chubut; y en la actualidad, frente al predominio del scoutismo católico, sea imposible la existencia del scoutismo laico.

En ambas instituciones observamos también los esfuerzos de sus fundadores por rescatar el espíritu original eliminado las características que lo habían ido empañando con el correr de los años y la acción de sus miembros. Es así como Baden Powell insiste en el carácter religioso y no militarista de los Boy Scouts y Vespignani en la espiritualidad de los Exploradores y la reducción del espíritu excursionista y de exteriorizaciones públicas y festivas. En el ámbito de Santa Cruz son más notorias las características que los hermanan: el interés permanente, prácticamente un atento control, por la formación integral del niño y el adolescente ; su fuerte sentimiento patriótico y nacionalista; el objetivo de trascender el ámbito escolar supliendo con su accionar la limitada oferta de actividades infantiles en la región; el establecer lazos permanentes con los niños y adolescentes de los otros colegios salesianos disminuyendo, en parte, el asilamiento demográfico de la zona; su enseñanza práctica que, en el caso de los salesianos coincidía con toda su impronta educativa, y el objetivo de, por medio de su acción, ser un freno contra las fuerzas socialistas que veían amenazadoras para la región.

En el plano ideológico, tanto los Exploradores de Don Bosco como los Boy Scouts fueron una herramienta eficaz para la tarea que, desde el gobierno central y en especial en las décadas de 1930 y 1940, se estaba llevando a cabo en los territorios patagónicos: nacionalizarlos, homogeneizarlos bajo el lema "Patria y Dios" e incorporarlos de manera efectiva a la Argentina.

Por ese motivo, si bien desde el punto de vista estrictamente religioso ambas instituciones podían ser consideradas rivales, el haber tenido muchos otros aspectos en común explica por qué, en las décadas mencionadas, se observa un avance del scoutismo católico por sobre el primigenio que era estrictamente laico. Y, en la región de Santa Cruz, al no haber existido esa rivalidad que analizamos para la zona de Buenos Aires, esa "submisión" de una institución laica - los Boy Scouts- a una de fuerte impronta católica - los Exploradoresfue mucho más rápida y menos traumática. 
PIERINI, M. de los M.

Artigo recebido em: 21/11/2019

Aprovado para publicação em: 01/02/2019

\section{THE EXPLORADORES DE DON BOSCO: THE EXTENSIÓN OF THE SALESIAN EDUCATIONAL WORK FURTHER THAN THE WALLS OF THE CLASSROOM (SANTA CRUZ, S. XX)}

ABSTRACT: The Salesian Congregation was born in Turin when Italy was going through a process of industrialization and strong secularism. The aim of this Congregation was to cater to children and adolescents in the popular sectores trascending mere school.To move to the Argentina they replicated the methodology implemented in Italy who joined the "Exploradores de Don Bosco". We will discuss how developed in Santa Cruz in the period of confrontation between the secular school and Salesian and between the Exploradores de Don Bosco and Boy Scouts. We will used the documentation provided by both institutions along with the testimonies of the ancient inhabitants of Santa Cruz.

KEYWORDS: Salesians. Santa Cruz. Secularism. Exploradores de Don Bosco. Boy Scouts.

\section{OS EXPLORADORES DE DOM BOSCO: A EXTESÃO DA TAREFA EDUCATIVA SALESIANA PARA ALÉM DAS PAREDES DA SALA DE AULA (SANTA CRUZ, S. XX)}

RESUMO: A Congregação Salesiana nasceu em Turim quando a Itália passava por um processo de industrialização e forte secularismo. O objetivo desta Congregação era atender as crianças e adolescentes dos setores populares, transcendendo o ambiente meramente escolar. Quando se mudaram para a Argentina, replicaram a metodologia implementada na Itália, que acrescentaram aos Exploradores de Dom Bosco. O objetivo deste artigo é mostrar como se desenvolveram em Santa Cruz durante o período de confronto entre as escolas secular e salesiana e entre os Exploradores de Dom Bosco e os Escoteiros. Utilizaremos a documentação fornecida por ambas as instituições juntamente com os depoimentos dos antigos moradores de Santa Cruz.

PALABRAS CLAVE: Salesianos. Santa Cruz. Secularismo. Exploradores de Dom Bosco. Escoteiros.

BiBLIOGRAFÍA

Asociación Nacional de Boy Scouts Argentinos. (1927) Requisitos para aspirantes. El Scout argentino. 
Asociación Nacional Boy Scouts Argentinos. Requisitos para aspirantes. Scouts de $3^{\circ}$ y $2^{\circ}$ clase. Buenos Aires: Talleres Gráficos Caracciolo y Plantié. s/f.

Asociación Nacional de Boy Scouts Argentinos. Memorias 1925 - 1926 y 1941 - 1942. Buenos Aires, Talleres Gráficos Flaiban.

BARBERIA, E.M. Los dueños de la tierra en la Patagonia Austral. 1880 - 1920. Río Gallegos: Universidad Federal de la Patagonia Austral. 1995.

BAEZA, B. "La escuela y la emergencia de "imprimir" nacionalidad en niños/as de la frontera chileno-argentina de Patagonia Central. El papel de los docentes como productores identitarios"; en: PIERINI, M. M. (Coord.) Docentes y alumnos. Protagonistas, organización y conflictos en las experiencias educativas patagónicas. Historia de la Educación en la Patagonia Austral, Tomo II. Río Gallegos: UNPA. 2008.

BEECHER, P.G. Félix Valenciano. Homenaje a un hombre altruista. La Opinión Austral, 20.8.2006.

BERTOLINI, P. Educación y Escultismo. Barcelona: Ed. Litúrgica española S.A. 1969.

BOHOSLAVSKY, E. "El Nacionalismo norpatagónico en los orígenes del peronismo (1930 1943)"; en: RAFART, G. y MASES, E. (Dir) El Peronismo, desde los Territorios a la Nación. Su historia en Río Negro y Neuquén (1943 - 1958) Neuquén: Universidad Nacional del Comahue. 2003.

BRACERAS HAEDO, A. El Scoutismo en la Argentina. Tribuna libre. Año II, № 54. 10.9.1919. BRUNO, C. Los Salesianos y las Hijas de María Auxiliadora en la Argentina. Buenos Aires: Instituto Salesiano de Artes Gráficas. Tomo I. 1981.

CAPIZZANO, H. Origen y fundación de los exploradores de Don Bosco (1915 - 1916) Buenos Aires. (mimeo). s/f.

CASALI, R. La Misión La Candelaria y la salud de la población Selk'nam (Tierra del Fuego 1895 - 1931). Rosario: Prohistoria.2013.

EXPLORADORES ARGENTINOS DE DON BOSCO. Disponível em $<$ https://donboscoexplorador.jimdo.com/>. Consultada en enero de 2019.

FOUCAULT, M. Surveiller et punir. Naissance de la prison. Paris: Gallimard.1975. 
PIERINI, M. de los M.

FRESIA, I.A. Niños cantores, gimnastas y músicos. Pedagogía del cuerpo, disciplinamiento y educación del gusto, 1900-1915 (mimeo) 2004.

FURLONG, G. Los Salesianos que hacen y escriben la Historia. Conferencia. 25.9.1971.

MAGALDI, J.B. Dos movimientos Scouts en la Argentina. Criterio. Año XII, 17.8.1939.

MARABINI, J. Los Salesianos del Sud (República Argentina) Trabajos y Riquezas. Contestación al Informe "Las Escuelas del Sud" del Dr.J.B. Zubiaur, vocal del Consejo de Educación. Buenos Aires: Escuela Tipográfica del Colegio Pío IX. 1906.

MARTINIC, M. La organización masónica en Magallanes. Primeras actividades. 1896 - 1910. Boletín de la Academia chilena de la Historia. Año I. XVIII. № 110. Año 2000- 2001. Págs. 151 163.

MONZÓN, C.J. El Colegio Santo Domingo de Guzmán, primeros años 1907-1930 (mimeo) 2003.

NICOLETTI, M.A. Indígenas y misioneros en la Patagonia: huellas de los salesianos en la cultura y religiosidad de los pueblos originarios. Buenos Aires: Continente. 2008.

Periódicos El Nacional (Río Gallegos), años 1922 y 1923; La Unión (Río Gallegos) años 1922,1928,1929,1940,1941; El Orden (Puerto Deseado) año 1945; La Verdad (San Julián), año 1948.

PODLUBNE, A.; CHIAPPE, M.; MÉNDEZ, L. M. Entre la Nación y el mundo. Orígenes del Movimiento Scout en la Argentina. El Perito Moreno y el Nahuel Huapi 19081945.Disertación presentada en el Octavo Congreso de Historia Social y Política de la Patagonia Argentino-Chilena Trevelin, Chubut, Argentina, 8 al 10 de octubre de 2009. 21 p.

Revista de Ex Alumnos de Don Bosco. 1941.

Scouts católicos de Baden Powell. s/f. Vida Scout. 1937.

VESPIGNANI, J. Los Exploradores de Don Bosco. 1842 - 1915. Buenos Aires: Escuela Tipográfica del Colegio Pío IX. 1918.

VESPIGNANI, J. Circulares, Cartas, Avisos. Para uso de los salesianos de la Inspectoría Argentina de San Francisco de Sales. Buenos Aires: Edición reservada .1922.

ZANATTA, L. Del Estado Liberal a la Nación Católica. Iglesia y Ejército en los orígenes del Peronismo. 1930 - 1943. Bernal: Universidad Nacional de Quilmes Ediciones.1996. 
MARIA de lOS MILAgros PIerINI: Profesora, Licenciada y Magister en Historia. Profesora Adjunta ordinaria responsable de las cátedras Historia Argentina I y Problemática de los Derechos Humanos del Profesorado en Historia de la Unidad Académica de Río Gallegos, Universidad Nacional de la Patagonia Austral. Desde el año 2001 integró el Programa "Constitución y desarrollo del Área de Historia de la Educación en la Patagonia Austral". OrCID: https://orcid.org/0000-0003-0634-2127

E-mail:mmpierini@gmail.com

Este periódico utiliza a licença Creative Commons Attribution 3.0, para periódicos de acesso aberto (Open Archives Iniciative - OAI). 